\title{
Use of green fluorescent protein (GFP) to study the invasion pathways of Edwardsiella tarda in in vivo and in vitro fish models
}

Department of Biological Sciences, Faculty of Science, National University of Singapore, 10 Kent Ridge Crescent Singapore 119260

\author{
S. H. M. Ling, X. H. Wang, L. Xie, T. M. Lim and K. Y. Leung \\ Author for correspondence: K. Y. Leung. Tel: +65 8747835. Fax: +65 7792486 \\ e-mail: dbslky@nus.edu.sg
}

Edwardsiella tarda is a fish pathogen that causes systemic infections in many food and ornamental fish. E. tarda PPD130/91 and PPD125/87 were selected as representatives of the virulent and avirulent groups, respectively, from eight fish isolates, and transformed with plasmids encoding either green fluorescent protein (pGFPuv) or blue fluorescent protein (pBFP2). Two host models were used to study the invasion pathway of $E$. tarda in vitro and in vivo. Epithelioma papillosum of carp (EPC) was used as the first model. Virulent and avirulent $E$. tarda strains were found to adhere to and invade EPC cells. Interactions between $E$. tarda and host cells examined under confocal microscopy and intracellular growth were followed at different time points. Bacterial internalization of PPD130/91 and PPD125/87 involved microfilaments and protein tyrosine kinase since cytochalasin $D$ (an inhibitor of microfilament polymerization) and genistein (an inhibitor of protein tyrosine kinase) prevented internalization. Confocal studies revealed co-localization of polymerized actin with bacteria. Staurosporine, a protein kinase $\mathrm{C}$ inhibitor, accelerated internalization of PPD125/87, whereas PD098059, a mitogenactivated protein kinase (MAPK) kinase inhibitor prevented internalization of PPD130/91. In the second model, blue gourami were infected with E. tarda intramuscularly. Mortalities were observed in PPD130/91(pGFPuv)-infected fish with high bacterial numbers detectable in all organs. PPD125/87(pBFP2)infected fish did not die and the bacterial population decreased over time. Mixed infections comprised of both PPD130/91 (pGFPuv) and PPD125/87(pBFP2), where inoculum size was similar to the single infections, caused mortalities in fish. High bacterial populations were noted only in the fish body muscle. The PPD125/87(pBFP2) population in the fish decreased after $5 \mathrm{~d}$. The number of PPD130/91(pGFPuv) also decreased in the fish organs, except for continued high growth in the body muscle. Histology revealed necrosis of the tissue (body muscle and liver) and fluorescent bacteria in fish that were infected with PPD130/91(pGFPuv) but not with PPD125/87(pBFP2). This study showed that fluorescent proteins are a useful tool for investigating bacterial host cell infection, and information elucidated here sheds new light on the interactions between $E$. tarda and its hosts.

Keywords: Edwardsiella tarda, GFP, carp epithelial cells, infection kinetics

\section{INTRODUCTION}

Edwardsiella tarda, a Gram-negative bacterium of the family Enterobacteriaceae, is the causative agent of one

Abbreviations: EPC, epithelioma papillosum of carp; GFP, green fluorescent protein; MAPK, mitogen-activated protein kinase. of the most serious bacterial diseases of freshwater and marine fish in both farmed and wild populations around the world. Outbreaks of the disease, called edwardsiellosis, have been recorded in a diverse array of commercially important fish, including eels (Wakabayashi \& Egusa, 1973), chinook salmon (Amandi et al., 1982), flounder (Nakatsugawa, 1983), 
tilapia (Kubota et al., 1981), carp (Sae-Oui et al., 1984), channel catfish (Meyer \& Bullock, 1973) and others. The bacterium has a broad host range and causes diseases in reptiles, birds (White et al., 1973) and mammals (Van Damme \& Vandepitte, 1984), including humans (Plumb, 1993). Typical symptoms of edwardsiellosis in fish are septicaemia with extensive skin lesions and swelling (Plumb, 1993). Haemorrhage and necrosis of the liver, spleen and other tissues are also evident. Eventually, the infection spreads through the internal organs and muscle with suppurative abscesses being the main characteristic.

Little information is available on what virulence factors may contribute to E. tarda infections. The pathogenic mechanism and the invasion pathways of E. tarda are not clear. Several virulence factors have been implicated, including haemolysins (Janda et al., 1991a; Hirono et al., 1997), dermatoxins (Ullah \& Arai, 1983), a lethal toxin (Suprapto et al., 1996), anti-phagocyte killing (Ainsworth \& Dexiang, 1990), congo-red binding and serum resistance (Janda et al., 1991b). There has been no study to correlate virulence factors of fish isolates with virulence in fish. In murine models, $\mathrm{LD}_{50}$ of human isolates did not correlate with plasmid content, chemotactic motility, serum resistance or exoenzymes including haemolysins (Janda et al., 1991b). The ability to invade epithelial cells is a common virulence character in various fish pathogens, such as Aeromonas bydrophila (Tan et al., 1998) and Vibrio species (Wang et al., 1998). However, the ability of fish isolates of E. tarda to penetrate and replicate in mammalian epithelial cells is in question. Janda et al. (1991a) reported that fish isolates were among a group that was not consistently positive for invasion of human HEp-2 cells. A human $E$. tarda isolate containing a mutation in the haemolysin gene was reported to be defective for entry into HEp-2 cells, suggesting that the phenotypes of cytotoxicity and invasion are linked (Strauss et al., 1997). Information on interactions between E. tarda and fish cells is lacking and this area therefore requires study in order to understand the initial pathogenetic process in fish.

The recent introduction of the green fluorescent protein (GFP) from the jellyfish Aequorea victoria as an endogenous fluorescent tag promises to provide a means of both rendering the bacteria visible and tracing their activity in living host cells (Prasher et al., 1992; Chalfie et al., 1994; Valdivia et al., 1996). Many mutants of GFP have been generated for improved fluorescence (Crameri et al., 1995). There are many advantages of tagging bacteria with GFP. It fluoresces independent of cofactors, substrates or any additional gene products. In addition, it is autonomous, sensitive, stable, specific, easy to use, non-toxic and does not interfere with cell growth and function (Chalfie et al., 1994; Valdivia et al., 1996). With such a tool, invasion pathways of E. tarda in fish and fish culture cells can be analysed using small doses of bacteria to mimic the process of naturally acquired E. tarda infections.

This study illustrates the usefulness of fluorescent proteins in tracking the fish pathogen, E. tarda, in vitro [epithelioma papillosum of carp (EPC) cells] and in vivo (blue gourami). Our purpose was to illustrate that $E$. tarda invade and replicate inside carp epithelial cells. At the same time, infections with virulent and avirulent strains were carried out in fish to study their different infection kinetics. By understanding the pathogenesis of edwardsiellosis, we hope to develop new approaches to combat this disease.

\section{METHODS}

Bacterial strains and media. The eight strains of E. tarda used in this study and their sources are listed in Table 1. All were fish isolates. These strains were tested using standard biochemical diagnostic kits (Microbact Identification Kit 24E, DP Diagnostics; and BBL Crystal Enteric/Nonfermenter ID System, Becton Dickinson), and their identities were confirmed according to the criteria of Farmer \& McWhorter (1984). Four transformed bacterial strains generated from this study are also listed in Table 1. Cultures were routinely grown in tryptic soy broth (TSB, Difco) or on tryptic soy agar (TSA; Difco) at $25^{\circ} \mathrm{C}$. Stock cultures were maintained at $-80^{\circ} \mathrm{C}$ in a suspension of TSB containing $25 \%(\mathrm{v} / \mathrm{v})$ glycerol. When required, the antibiotics ampicillin, tetracycline, neomycin, chloramphenicol and streptomycin were added at final concentrations of $50,12 \cdot 5,50,34$ and $50 \mu \mathrm{g} \mathrm{ml}^{-1}$, respectively.

Haemolysin production was determined with $5 \%$ heparinized blue gourami whole blood in TSA. The amount of haemolysin produced was estimated from the diameter of clear zones after $24 \mathrm{~h}$ incubation.

Survival assay in blue gourami serum. Blood was collected from the caudal vein of naive blue gourami, and serum was separated from the clot by centrifugation at $4{ }^{\circ} \mathrm{C}$. Bacteria grown in TSB at $25^{\circ} \mathrm{C}$ for $24 \mathrm{~h}$ were collected by centrifugation and washed three times in PBS $(137 \mathrm{mM} \mathrm{NaCl}$, $4.3 \mathrm{mM} \mathrm{Na} \mathrm{HPO}_{4}, 1.4 \mathrm{mM} \mathrm{KH} \mathrm{PO}_{4}, \mathrm{pH} 7 \cdot 2$ ). The cell suspension was mixed with blue gourami serum to give a final serum concentration of $50 \%$ and the bacterial count was adjusted to approximately $5 \times 10^{7}$ c.f.u. $\mathrm{ml}^{-1}$. The microcentrifuge tubes were incubated at $25^{\circ} \mathrm{C}$ and samples were removed at $1 \mathrm{~h}$ for serial dilutions and plate counts on TSA. Serum survival ability was calculated by dividing the number of viable bacteria after the serum treatment by the number of viable bacteria before treatment, as described previously (Leung et al., 1995). A value greater than one was taken as indicating serum resistance and a value less than one was taken as indicating serum sensitivity.

$\mathbf{L D}_{50}$ determinations. To assess the virulence of the E. tarda strains, $\mathrm{LD}_{50}$ determination was conducted using naive blue gourami, Trichogaster trichopterus (Pallas). The fish, each weighing approximately $13 \mathrm{~g}$, were purchased from commercial fish farms and acclimatized for more than 1 month. Three groups of 10 fish were injected intramuscularly with $0 \cdot 1 \mathrm{ml}$ PBS-washed bacterial cells adjusted to the required concentrations. Fish were monitored for mortalities for $7 \mathrm{~d}$ and $\mathrm{LD}_{50}$ values were calculated by the method of Reed \& Muench (1938).

Cell culture. All tissue culture reagents were obtained from Gibco. EPC cells from Cyprinus carpio (Wolf \& Mann, 1980) were grown in minimal essential medium (MEM) with Hanks' balanced salts solution (Sigma), $10 \mathrm{mM}$ HEPES pH 7.3, $2 \mathrm{mM}$ glutamine, $0.23 \% \mathrm{NaHCO}_{3}$ and $10 \%(\mathrm{v} / \mathrm{v})$ heat-inactivated 
Table 1. E. tarda strains used, and their sources and virulence characteristics

\begin{tabular}{|c|c|c|c|c|c|c|}
\hline Strains & Source* & $\begin{array}{l}\text { Antibiotic } \\
\text { resistance } \\
\text { profile } †\end{array}$ & $\begin{array}{l}\text { Cytotoxic } \\
\text { effect on } \\
\text { EPC } \\
\text { cells } \ddagger\end{array}$ & $\begin{array}{l}\text { Survival in } \\
\text { serum } \mathbb{S}\end{array}$ & $\begin{array}{l}\text { Haemolysin } \\
\text { production } \|\end{array}$ & $\begin{array}{l}\mathrm{LD}_{50} \\
\text { (intramuscular } \\
\text { injection) } 9\end{array}$ \\
\hline AL9379 & $\begin{array}{l}\text { Channel catfish, Department } \\
\text { of Fishery, Auburn University, } \\
\text { USA }\end{array}$ & Ap, Neo & Slow & $1 \cdot 71 \pm 0 \cdot 17$ & + & $10^{5 \cdot 9}$ \\
\hline PPD499/84 & Diseased fish, PPD, Singapore & Ap, Tet & Rapid & $1 \cdot 57 \pm 0 \cdot 13$ & + & $>10^{7 \cdot 5}$ \\
\hline PPD453/86 & Arowana, PPD, Singapore & Ap & Slow & $0 \cdot 76 \pm 0 \cdot 16$ & + & $>10^{7 \cdot 2}$ \\
\hline PPD76/87 & Sword tail, PPD, Singapore & Str, Tet & Slow & $0 \cdot 001 \pm 0 \cdot 0005$ & + & $>10^{7 \cdot 4}$ \\
\hline PPD125/87 & Guppy, PPD, Singapore & - & Rapid & $1 \cdot 61 \pm 0 \cdot 18$ & + & $>10^{7 \cdot 4}$ \\
\hline PPD125/87(pBFP2) & This study & Ap & Rapid & $1.75 \pm 0.07$ & + & $>10^{7 \cdot 6}$ \\
\hline PPD125/87(pGFPuv) & This study & Ap & Rapid & $1 \cdot 88 \pm 0 \cdot 21$ & + & $>10^{7 \cdot 4}$ \\
\hline PPD200/87 & Discus, PPD, Singapore & Tet & Slow & $0 \cdot 61 \pm 0 \cdot 13$ & - & $>10^{7 \cdot 4}$ \\
\hline PPD129/91 & Tilapia, PPD, Singapore & - & Rapid & $2 \cdot 09 \pm 0 \cdot 14$ & + & $>10^{7 \cdot 3}$ \\
\hline PPD130/91 & Serpae tetra, PPD, Singapore & - & Slow & $2 \cdot 13 \pm 0 \cdot 18$ & + & $10^{5 \cdot 2}$ \\
\hline PPD130/91(pBFP2) & This study & Ap & Slow & $2 \cdot 31 \pm 0 \cdot 35$ & + & $10^{5 \cdot 1}$ \\
\hline PPD130/91(pGFPuv) & This study & Ap & Slow & $2 \cdot 32 \pm 0 \cdot 18$ & + & $10^{5 \cdot 2}$ \\
\hline
\end{tabular}

* PPD, Primary Production Department.

† To determine antibiotic resistance, ampicillin (Ap), tetracycline (Tet), neomycin (Neo), chloramphenicol (Chl) and streptomycin (Str) were used at 50, 12.5, 50, 34 and $50 \mu \mathrm{g} \mathrm{ml}^{-1}$, respectively.

$\ddagger$ Based on the morphological changes in EPC cells as described in Results. Data were obtained from three independent experiments.

$\$$ Calculated by dividing the viable bacterial population after serum treatment by the initial population before serum treatment. A value greater than one was scored as serum-resistant, whilst a value below one was scored as serum-sensitive. Data were obtained from three independent experiments.

$\|$ Measured by the diameter of clear zones after $24 \mathrm{~h}$ incubation on TSA containing $5 \%$ heparinized blue gourami whole blood. Data were obtained from three independent experiments.

I Calculated by the method of Reed \& Muench (1938). A value of less than $10^{6}$ was scored as virulent. Sample size was 10 fish per tank.

foetal bovine serum at $25^{\circ} \mathrm{C}$ in a $5 \%(\mathrm{v} / \mathrm{v}) \mathrm{CO}_{2}$ atmosphere. Cells were grown in $75 \mathrm{~cm}^{2}$ flasks and divided at least once a week by trypsin/EDTA treatment and dilution at $1: 10$ in fresh media.

Cytoskeleton and signal transduction inhibitors. Inhibitors and their concentrations used are listed in Table 3. The concentrations of inhibitors used were according to the manufacturer's recommendations. For genistein and staurosporine, concentrations used were those described by Rosenshine et al. (1992). DMSO was used to dissolve all chemicals. Prior to use, the inhibitors were further diluted in MEM supplemented with $10 \%$ foetal bovine serum and added to the cultured fish cells.

Morphological changes in EPC cells induced by $E$. tarda strains. Studies on morphological changes were conducted by seeding $5 \times 10^{5}$ EPC cells into each well of a 24 -well tissue culture plate (Falcon), and then performed as described by Tan et al. (1998) and Wang et al. (1998). Five millilitre stationary-phase cultures were prepared by inoculating TSB with E. tarda strains from frozen glycerol stocks and incubating overnight at $25^{\circ} \mathrm{C}$. Three hours prior to infection of the EPC cells, mid-exponential-phase cultures were prepared by diluting the overnight culture 1:10 in fresh TSB and incubating at $25^{\circ} \mathrm{C}$ for $3 \mathrm{~h}$. Bacterial cells were pelleted and washed three times in PBS before being added to each tissue culture well (approx. $5 \times 10^{5}$ bacteria in $5 \mu \mathrm{l}$ ). After inoculation, the 24 well tissue culture plate was centrifuged $\left(800 \mathrm{~g}, 5 \mathrm{~min}, 4^{\circ} \mathrm{C}\right)$ and then incubated at $25^{\circ} \mathrm{C}$. The morphology of EPC cells was examined using an Axiovert $25 \mathrm{CFL}$ phase-contrast inverted microscope (Carl Zeiss) at $\times 200$ magnification.

Adherence and internalization assays. These were performed as described by Elsinghorst (1994) and Wang et al. (1998) with minor modifications. EPC monolayers were grown for $72 \mathrm{~h}$ in $24-$ well tissue culture plates to $100 \%$ confluence. They were then infected with E. tarda, at m.o.i.s of $1: 1$ and $1: 3$, for $30 \mathrm{~min}$ at $25^{\circ} \mathrm{C}$ as described above. A control, Escherichia coli strain TOP10F' (Clontech) was also included. To measure the number of bacteria adhering to the monolayers, the monolayers were washed six times with Hanks' salts, lysed with $1 \%(\mathrm{v} / \mathrm{v})$ Triton X-100 in PBS, and then the bacterial numbers quantified by plate counting. To measure internalization, the monolayers were washed three times with Hanks' salts to remove bacteria remaining in the medium and incubated for $2 \mathrm{~h}$ in MEM containing gentamicin $\left(100 \mu \mathrm{g} \mathrm{ml} \mathrm{m}^{-1}\right.$ ) (Sigma) to kill any residual extracellular bacteria. Afterwards, the EPC cells were washed three times with Hanks' salts to remove any remaining gentamicin. One millilitre of $1 \%$ Triton X-100 in PBS was added to each well to lyse the EPC cells and the number of viable intracellular bacteria was quantified by plate counting. The adherence and internalization rates were calculated from the mean of two wells in quadruplicate experiments. In studies of different signal transduction inhibitors, EPC monolayers were incubated with each of the inhibitors for $30 \mathrm{~min}$ prior to infection and throughout the 
internalization assay. The number of viable intracellular bacteria was determined after $2.5 \mathrm{~h}$ as described above. The number of viable intracellular bacteria was expressed as a percentage of untreated controls and was determined in triplicate experiments. To ensure that the E. tarda strains were not affected by the inhibitors, bacterial viability counts were determined after $2.5 \mathrm{~h}$ of treatment. Viabilities of bacteria were expressed as a percentage of untreated controls and were determined in triplicate experiments.

Intracellular replication assay. This was performed as described by Leung \& Finlay (1991). The intracellular replication of strains PPD130/91 and PPD125/87 was assessed as described for the internalization assay with the following modifications. Instead of treating the cells with $1 \%$ Triton X100 in PBS after gentamicin treatment, the monolayers were washed with Hanks' salts and fresh MEM containing $10 \mu \mathrm{g}$ gentamicin $\mathrm{ml}^{-1}$ was added to inhibit any growth of the remaining extracellular bacteria. This medium was removed after incubation for the appropriate time (at 3.5, 4.5, $5 \cdot 5$ and $6.5 \mathrm{~h}$ post-inoculation), the monolayers were lysed with $1 \%$ Triton X-100 in PBS and the number of viable intracellular bacteria was quantified as described for the internalization assay.

Transformation of $E$. tarda strains with pGFPuv and pBFP2. Plasmids pGFPuv and pBFP2 (Clontech) were transformed into E. tarda strains using a standard $\mathrm{CaCl}_{2}$ transformation protocol (Sambrook et al., 1989). Plasmids pGFPuv and pBFP2 have an ampicillin resistance marker and transformed E. tarda were plated out on TSA containing ampicillin. Colonies that were resistant to ampicillin and fluoresced bright green (pGFPuv) or blue (pBFP2) under UV light were selected.

Plasmid stability. This assay was performed to check for the ability of transformed E. tarda PPD130/91(pGFPuv) and PPD125/87(pBFP2) to retain their plasmids. A single colony of the bacteria was inoculated into a test tube containing $5 \mathrm{ml}$ TSB. This bacterial culture was continuously subcultured by reinoculating to another test tube containing $5 \mathrm{ml}$ fresh TSB daily for $7 \mathrm{~d}$. The bacterial culture was sampled daily for $7 \mathrm{~d}$ to quantify the bacterial number by plate counting. Plasmid stability was checked by examining the ability of the bacterial colonies to fluoresce with the aid of an UV lightbox.

Confocal microscopy and immunofluorescence study. EPC cells were seeded onto glass coverslips and placed in each well of a 24-well tissue culture plate, as described above. The monolayers were then inoculated with $5 \mu \mathrm{l}$ E. tarda tagged with pGFPuv, prepared as above. At appropriate time intervals, the coverslips were removed and examined using a Nikon Optiphot microscope attached to a Bio-Rad MRC 500 confocal system (Lasersharp). A blue laser, of excitation wavelength $488 \mathrm{~nm}$, was used to view E. tarda tagged with pGFPuv. Optical sectioning of infected EPC cells was carried out serially at $2 \mu \mathrm{m}$ intervals along the apical and basal axes of the cell.

Rhodamine phalloidin (Molecular Probes) was used to label actin in EPC cells according to the manufacturer's instructions. Labelled actin was visible under the confocal laser scanning microscope using an excitation wavelength of $514 \mathrm{~nm}$. Images obtained at $\times 600$ to $\times 1800$ were photographed with a Polaroid freeze-frame recorder using Kodak T-max 100 and Kodak colour ISO 100 film. The frequency of the co-localization of actin patches and bacteria was also measured as number of colocalizations per $100 \mathrm{EPC}$ cells in triplicate experiments.
Study of infection kinetics of $E$. tarda in blue gourami. The intramuscular route of administration was used in the study of the infection kinetics of E. tarda in vivo. There were five treatment groups - four single infections and one mixed. For the single infections, fish were infected separately with $E$. tarda PPD130/91, PPD130/91(pGFPuv), PPD125/87 or PPD125/87(pBFP2) at an inoculum size of $10^{5}$ c.f.u. In the mixed infection study, fish were infected with E. tarda PPD130/91(pGFPuv) and PPD125/87(pBFP2) in a 1:1 ratio, with $5 \times 10^{4}$ c.f.u. of each strain. The fish were challenged with $0.1 \mathrm{ml}$ bacterial suspension via intramuscular injection. A control group of fish each received $0 \cdot 1 \mathrm{ml}$ sterile PBS. For $7 \mathrm{~d}$, four fish from each group were sampled daily. The gall bladder, heart, intestine, kidney, liver and spleen were aseptically removed. Blood was collected aseptically from the caudal vein. A piece of body muscle dissected from the site of injection, measuring approximately $1 \times 1 \mathrm{~cm}$, was also taken. The samples from each treatment were pooled together by organ type and placed into sterile sample bags (Whirl-Pak). They were then diluted with $1 \mathrm{ml}$ PBS and homogenized with a Stomacher Lab-Blender, model 80 (Seward Medical). The homogenates were serially diluted and plated in triplicate onto appropriate media, either TSA or TSA containing ampicillin, and incubated at $25^{\circ} \mathrm{C}$ for $48 \mathrm{~h}$. Bacterial counts were then done with the aid of an UV lightbox.

Histological examination of the body muscle and liver of blue gourami. Fish were infected with PPD125/87(pBFP2), PPD130/91(pGFPuv) and the mixed inoculum as described above. A control group received only PBS. At $5 \mathrm{~d}$ postinoculation, body muscle and whole liver samples were dissected from fish from each treatment group. These tissues were immediately mounted in Jung Tissue Freezing Medium (Leica Instruments) before being snap-frozen in liquid nitrogen and then cut into $15 \mu \mathrm{m}$ sections on a cryostat (model CM1850; Leica Instruments). These tissue sections were then examined using an Axiovert $25 \mathrm{CFL}$ phase-contrast inverted microscope (Carl Zeiss) at $\times 200$ and $\times 1000$ magnifications. To view the fluorescent bacteria, a blue filter of excitation wavelength $488 \mathrm{~nm}$ was used. Images were photographed with a camera attached to the microscope using Kodak colour ISO 100 film.

Statistical analysis. All data from morphological, adherence and internalization assays were expressed as mean \pm sEM. The data were analysed using one-way ANOva and a Duncan multiple range test (SAS software, SAS Institute). Values of $P<0.05$ were considered significant.

\section{RESULTS}

\section{Characterization of $E$. tarda strains}

The eight strains of E. tarda isolated from fish were characterized based on virulence characteristics such as antibiotic resistance profile, haemolysin production, serum resistance and $\mathrm{LD}_{50}$ values in blue gourami (Table 1). Six of the eight strains (PPD200/87, PPD499/84, PPD453/86, PPD76/87, PPD129/91 and PPD125/87) were classified as avirulent due to their higher $\mathrm{LD}_{50}$ values $\left(10^{7 \cdot 2}\right.$ to $>10^{7 \cdot 5}$ ) (Table 1$)$. Only two strains (PPD130/91 and AL9379) were classified as virulent, having $\mathrm{LD}_{50}$ values lower than $10^{6}$. All the E. tarda strains examined, except one avirulent strain, PPD200/87, produced haemolysins (Table 1). All E. tarda strains except three avirulent strains, PPD76/87, PPD453/86 and PPD200/87, were serum-resistant 
Table 2. Proportion of adherent and intracellular E. tarda strains in EPC cell cultures

Values were recorded as mean \pm SEM for four trials, each in triplicate. Within columns 3 and 4 , values followed by different superscript letters are significantly different $(P<0 \cdot 05)$.

\begin{tabular}{|c|c|c|c|}
\hline Strain & $10^{-5} \times$ Inoculum & Adherence $(\%)^{*}$ & $\begin{array}{c}\text { Internalization } \\
(\%) \dagger\end{array}$ \\
\hline \multicolumn{4}{|l|}{ Virulent } \\
\hline \multirow[t]{2}{*}{ AL9379 } & $4 \cdot 4 \pm 0 \cdot 5$ & $104 \cdot 2 \pm 10 \cdot 4^{a}$ & $39 \cdot 7 \pm 3 \cdot 1^{a}$ \\
\hline & $11 \cdot 7 \pm 0 \cdot 8$ & $102 \cdot 4 \pm 7 \cdot 3^{a}$ & $34 \cdot 7 \pm 0 \cdot 5^{a}$ \\
\hline \multirow[t]{2}{*}{ PPD130/91 } & $4 \cdot 8 \pm 0 \cdot 8$ & $4 \cdot 1 \pm 0 \cdot 7^{b}$ & $7 \cdot 2 \pm 0 \cdot 5^{b}$ \\
\hline & $11 \cdot 9 \pm 1 \cdot 6$ & $4 \cdot 0 \pm 0 \cdot 6^{b}$ & $6 \cdot 7 \pm 0 \cdot 7^{b}$ \\
\hline \multirow[t]{2}{*}{ PPD130/91(pBFP2) } & $5 \cdot 6 \pm 0 \cdot 4$ & $6 \cdot 3 \pm 0 \cdot 4^{b}$ & $7 \cdot 5 \pm 0 \cdot 4^{b}$ \\
\hline & $13 \cdot 6 \pm 1 \cdot 8$ & $6 \cdot 3 \pm 0 \cdot 5^{b}$ & $7 \cdot 6 \pm 0 \cdot 4^{b}$ \\
\hline \multirow[t]{2}{*}{ PPD130/91(pGFPuv) } & $4 \cdot 3 \pm 0 \cdot 3$ & $4 \cdot 2 \pm 0 \cdot 9^{b}$ & $7 \cdot 8 \pm 0 \cdot 7^{b}$ \\
\hline & $10 \cdot 9 \pm 0 \cdot 4$ & $4 \cdot 0 \pm 0 \cdot 9^{b}$ & $7 \cdot 4 \pm 0 \cdot 9^{b}$ \\
\hline \multicolumn{4}{|l|}{ Avirulent } \\
\hline \multirow[t]{2}{*}{ PPD499/84 } & $4 \cdot 7 \pm 0 \cdot 5$ & $149 \cdot 0 \pm 7 \cdot 0^{c}$ & $20 \cdot 8 \pm 3 \cdot 4^{c}$ \\
\hline & $12 \cdot 1 \pm 1 \cdot 0$ & $146 \cdot 5 \pm 3 \cdot 0^{c}$ & $14 \cdot 7 \pm 0 \cdot 2^{c}$ \\
\hline \multirow[t]{2}{*}{ PPD453/86 } & $5 \cdot 1 \pm 0 \cdot 3$ & $30 \cdot 3 \pm 1 \cdot 7^{d}$ & $4 \cdot 0 \pm 0 \cdot 4^{d}$ \\
\hline & $14.9 \pm 1.9$ & $21 \cdot 2 \pm 2 \cdot 4^{d}$ & $2 \cdot 4 \pm 0 \cdot 3^{d}$ \\
\hline \multirow[t]{2}{*}{ PPD76/87 } & $3 \cdot 1 \pm 1 \cdot 0$ & $27 \cdot 0 \pm 1 \cdot 6^{d}$ & $4 \cdot 2 \pm 0 \cdot 3^{d}$ \\
\hline & $9 \cdot 2 \pm 0 \cdot 01$ & $24 \cdot 6 \pm 2 \cdot 4^{d}$ & $3 \cdot 6 \pm 0 \cdot 3^{d}$ \\
\hline \multirow[t]{2}{*}{ PPD125/87 } & $4 \cdot 8 \pm 0 \cdot 2$ & $100 \cdot 8 \pm 1 \cdot 9^{a}$ & $16 \cdot 5 \pm 3 \cdot 0^{c}$ \\
\hline & $12 \cdot 0 \pm 0 \cdot 7$ & $103 \cdot 2 \pm 0 \cdot 7^{a}$ & $16 \cdot 7 \pm 3 \cdot 4^{c}$ \\
\hline \multirow[t]{2}{*}{ PPD125/87(pBFP2) } & $5 \cdot 1 \pm 0 \cdot 2$ & $26 \cdot 4 \pm 2 \cdot 5^{d}$ & $14 \cdot 6 \pm 2 \cdot 9^{c}$ \\
\hline & $12 \cdot 8 \pm 1 \cdot 4$ & $23 \cdot 0 \pm 2 \cdot 8^{d}$ & $16 \cdot 8 \pm 2 \cdot 6^{c}$ \\
\hline \multirow[t]{2}{*}{ PPD125/87(pGFPuv) } & $4 \cdot 8 \pm 0 \cdot 3$ & $22 \cdot 1 \pm 3 \cdot 9^{d}$ & $13 \cdot 1 \pm 2 \cdot 1^{c}$ \\
\hline & $12 \cdot 0 \pm 1 \cdot 2$ & $21 \cdot 9 \pm 3 \cdot 9^{d}$ & $13 \cdot 1 \pm 2 \cdot 2^{c}$ \\
\hline \multirow[t]{2}{*}{ PPD200/87 } & $5 \cdot 7 \pm 0 \cdot 2$ & $2 \cdot 0 \pm 0 \cdot 3^{e}$ & $1 \cdot 7 \pm 0 \cdot 1^{e}$ \\
\hline & $17 \cdot 2 \pm 5 \cdot 6$ & $2 \cdot 0 \pm 0 \cdot 3^{e}$ & $1 \cdot 2 \pm 0 \cdot 2^{e}$ \\
\hline \multirow[t]{2}{*}{ PPD129/91 } & $5 \cdot 3 \pm 0 \cdot 2$ & $28 \cdot 9 \pm 2 \cdot 1^{d}$ & $4 \cdot 4 \pm 0 \cdot 4^{d}$ \\
\hline & $13 \cdot 1 \pm 1 \cdot 7$ & $25 \cdot 8 \pm 3 \cdot 6^{d}$ & $3 \cdot 6 \pm 0 \cdot 3^{d}$ \\
\hline \multicolumn{4}{|l|}{ Control } \\
\hline \multirow[t]{2}{*}{ Escherichia coli $\mathrm{TOP} 10 \mathrm{~F}^{\prime}$} & $7 \cdot 9 \pm 0 \cdot 2$ & $2 \cdot 3 \pm 0 \cdot 2^{e}$ & $0 \cdot 56 \pm 0 \cdot 08^{f}$ \\
\hline & $24 \cdot 4 \pm 0 \cdot 7$ & $1 \cdot 4 \pm 0 \cdot 3^{e}$ & $0 \cdot 43 \pm 0 \cdot 05^{f}$ \\
\hline
\end{tabular}

* Adherence is expressed as percentage of bacteria still adherent after washing without gentamicin treatment $(n=4)$.

†Internalization is expressed as percentage of input bacteria surviving after gentamicin treatment for $2 \mathrm{~h}(n=4)$.

(Table 1). Of the three serum-sensitive E. tarda strains, PPD76/87 was found to be particularly sensitive.

\section{Interactions between E. tarda and EPC cells}

All E. tarda strains examined adhered to and invaded EPC cells (Table 2). Adherence and internalization rates were similar regardless of the m.o.i. The adherence rates were always higher than internalization rates, with the exception of PPD130/91. The internalization rate of the virulent strains ranged from 6.7 to $39.7 \%$. Among these strains, AL9379 had the highest internalization rate, together with a high adherence rate. Avirulent strains all had internalization rates which were less than $4.4 \%$, except PPD499/84 and PPD125/87. These two strains exhibited greater adherence $(>100 \%)$ to EPC cells, compared to the other avirulent strains. Adherence rates greater than $100 \%$ may be due to high adherence capability and rapid bacterial growth of these strains during the $30 \mathrm{~min}$ incubation in MEM. The Escherichia coli control did not adhere to or invade EPC cells, indicating that invasion by $E$. tarda is a specific process.

E. tarda strains were cytotoxic and two groups inducing different patterns of cytopathic changes in EPC cells were observed (Table 1). Rapidly cytotoxic strains randomly formed gaps in the infected EPC monolayers 2-3 h post-inoculation. Slowly cytotoxic strains did not form gaps or holes in the infected monolayer until $8 \mathrm{~h}$ post-inoculation. When incubated with PPD125/87 (a rapidly cytotoxic strain), infected EPC cells detached from one another and appeared slightly retracted at $1 \mathrm{~h}$ post-inoculation. Some EPC cells at randomly distributed points retracted more than others to form gaps in 
Table 3. Effect of inhibitors of bacterial invasion on internalization of E. tarda strains by EPC cells

Values represent the ratio of gentamicin-resistant bacteria in the presence of inhibitor to gentamicin-resistant bacteria without inhibitor and are expressed as percentages (mean \pm SEM; $n=4)$. Values followed by an asterisk are significantly different from the untreated control $(P<0 \cdot 05)$.

\begin{tabular}{|c|c|c|c|}
\hline Inhibitor & Class & PPD130/91 & PPD125/87 \\
\hline None & Control & 100 & 100 \\
\hline DMSO $(0 \cdot 4 \%)$ & Solvent & $96 \cdot 5 \pm 13 \cdot 5$ & $100 \cdot 8 \pm 9 \cdot 3$ \\
\hline Genistein $(150 \mu \mathrm{M})$ & Protein tyrosine kinase inhibitor & $41 \cdot 5 \pm 5 \cdot 7 *$ & $34 \cdot 5 \pm 5 \cdot 9 *$ \\
\hline Staurosporine $(0.005 \mu \mathrm{M})$ & Protein kinase $\mathrm{C}$ inhibitor & $95 \cdot 9 \pm 7 \cdot 1$ & $170 \cdot 4 \pm 18 \cdot 7 *$ \\
\hline PD098059 $(20 \mu \mathrm{M})$ & MAPK kinase inhibitor & $50 \cdot 8 \pm 7 \cdot 5 *$ & $100 \cdot 2 \pm 10 \cdot 3$ \\
\hline Cytochalasin $\mathrm{D}\left(0 \cdot 1 \mu \mathrm{g} \mathrm{ml}^{-1}\right)$ & Microfilament inhibitor & $16 \cdot 1 \pm 1 \cdot 0^{*}$ & $3 \cdot 9 \pm 1 \cdot 0^{*}$ \\
\hline
\end{tabular}
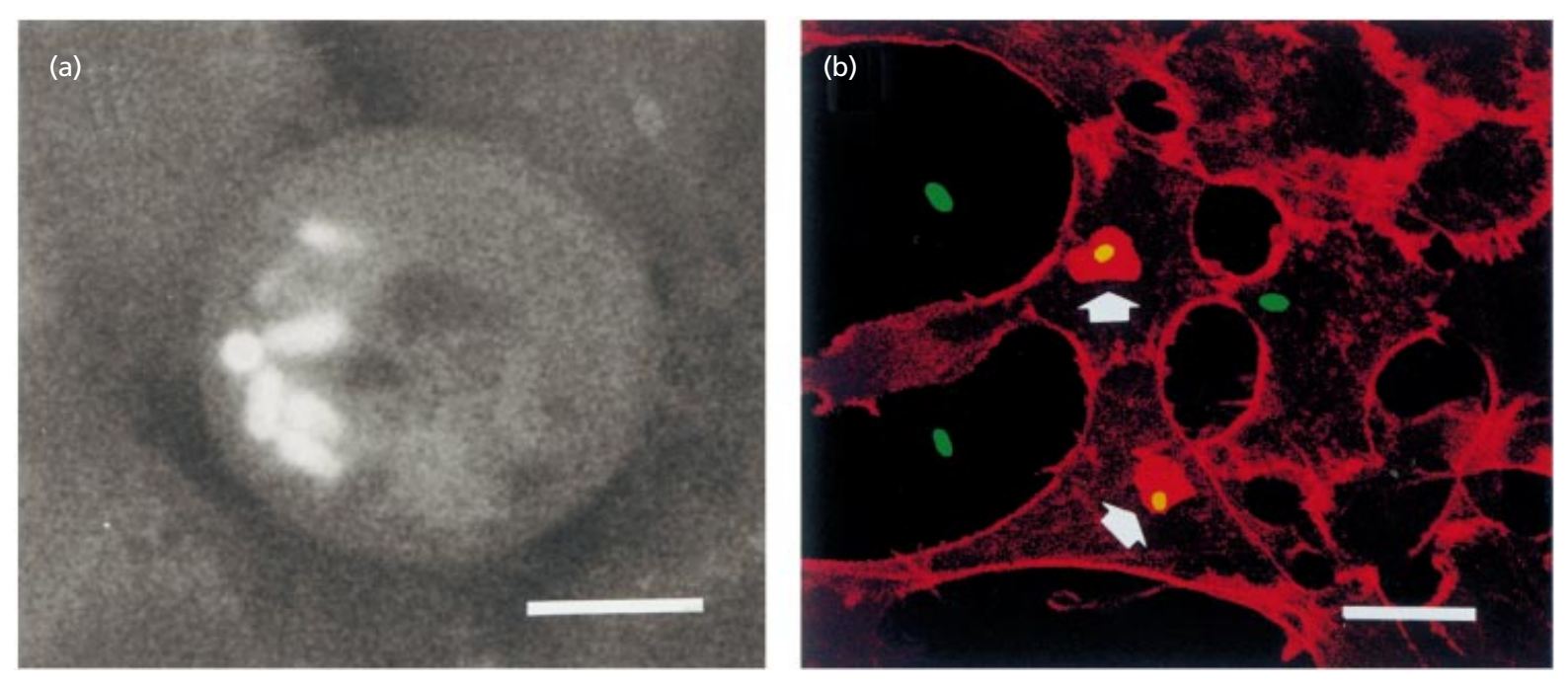

Fig. 1. Confocal micrographs of EPC cells infected with E. tarda PPD130/91(pGFPuv). (a) Confocal optical section of an EPC cell infected with PPD130/91(pGFPuv) $8 \mathrm{~h}$ post-inoculation. There are many intracellular bacteria inside the rounded EPC cell. (b) Micrograph of the overlay of two fields taken using two different excitation wavelengths. Rhodamine-phalloidin was used to stain actin filaments (red) in EPC cells whereas E. tarda PPD130/91(pGFPuv) is green due to the plasmid pGFPuv. Areas where the bacteria appear to co-localize with actin patches are yellow (marked by arrow). Bars: (a) $5 \mu \mathrm{m}$; (b) $10 \mu \mathrm{m}$.

the monolayer. These gaps continued to enlarge $(2 \mathrm{~h}$ post-inoculation) over the monolayer with time. Finally, by $3 \mathrm{~h}$ post-inoculation, the remaining cells that bordered the holes became rounded, detached from the wells and lysed. However, when inoculated with $E$. tarda PPD130/91 (a slowly cytotoxic strain), the monolayer showed no change in morphology at the early time points, retaining a morphology similar to the control group. Only after $8 \mathrm{~h}$ did the monolayer detach from the wells, leaving only floating, rounded, ghost-like dead cells.

\section{Intracellular replication of E. tarda strains in EPC cells}

Both PPD130/91 and PPD125/87 were able to replicate inside EPC cells. The number of PPD130/91 inside the
EPC cells increased significantly every hour throughout the experimental period, from $5.0 \times 10^{4}(2.5 \mathrm{~h}$ postinoculation) to $7 \cdot 0 \times 10^{5}(6.5 \mathrm{~h}$ post-inoculation). The number of PPD125/87 also increased from $1.4 \times 10^{5}$ c.f.u. $\left(2.5 \mathrm{~h}\right.$ post-inoculation) to $2 \cdot 1 \times 10^{5}$ c.f.u. $(3.5 \mathrm{~h}$ post-inoculation). Addition of gentamicin to inhibit any growth of the remaining extracellular bacteria slowed down morphological change in the PPD125/87-infected monolayers for $3.5 \mathrm{~h}$. However, the intracellular bacterial population sampled at $4.5 \mathrm{~h}$ post-inoculation decreased $\left(2.0 \times 10^{5}\right.$ c.f.u. $)$. At $6.5 \mathrm{~h}$ post-inoculation, there was further reduction in the intracellular population of PPD125/87 in the EPC cells $\left(1 \cdot 1 \times 10^{5}\right.$ c.f.u.). This decrease in bacterial numbers correlated with the ongoing changes in EPC cell morphology and the monolayers were eventually lysed. Thus, the decrease in bacterial numbers could be due to intracellular bacteria 

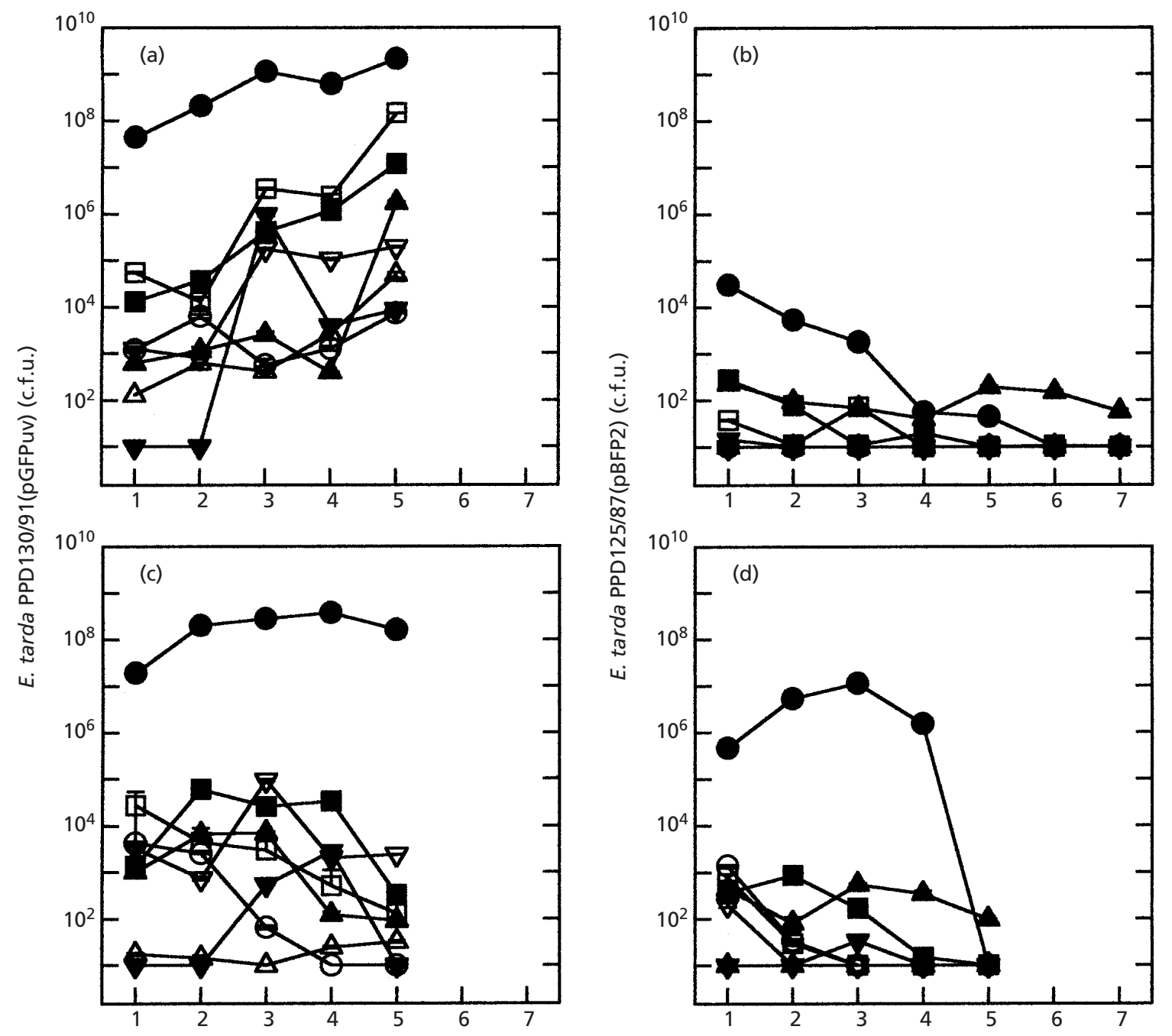

Time after infection (d)

Fig. 2. Infection kinetics of $E$. tarda strains in blue gourami. Single infection kinetics of (a) PPD130/91(pGFPuv) and (b) PPD125/87(pBFP2). (c, d) Mixed infection kinetics of PPD130/91(pGFPuv) together with PPD125/87(pBFP2). (c) PPD130/91(pGFPuv); (d) PPD125/87(pBFP2). For the single infections, each fish received $1.0 \times 10^{5}$ c.f.u. (100 $\mu$ ) PPD130/91(pGFPuv) or $1.2 \times 10^{5}$ c.f.u. (100 $\mu$ l) PPD125/87(pBFP2) intramuscularly. For the mixed infection, each fish received $1.2 \times 10^{5}$ c.f.u. (100 $\mu \mathrm{l}$ ) of a mixed inoculum comprised of PPD130/91(pGFPuv) and PPD125/87(pBFP2) in a 1:1 ratio, intramuscularly. Four fish were used per datum point. The error bars represent mean \pm SEM of $E$. tarda per sample in triplicate. Moribund fish were observed from day 3 onwards in the single infection of PPD130/91(pGFPuv) and in the mixed infection. Sampling was done until day 5 of the experiment, when all fish in these two treatment groups were dead. There was no mortality in the single infection of PPD125/87(pBFP2). Fish in this treatment group were sampled until day 7 of the experiment, as indicated. Blood $(\bigcirc)$, body muscle (O), liver $(\square)$, kidney ( $\square$ ), gall bladder $(\triangle)$, spleen $(\boldsymbol{\Delta})$, heart $(\nabla)$ and intestine $(\boldsymbol{\nabla})$ were dissected and homogenized and the number of bacteria in each was determined by plating homogenates onto TSA supplemented with ampicillin.

being killed by extracellular gentamicin 'leaking' into the non-intact EPC cell monolayers.

\section{Effects of inhibitors on internalization of $E$. tarda strains in EPC cells}

Bacterial uptake usually involves the exploitation of host cell functions to facilitate invasion. Different classes of inhibitors (Table 3) were used to better understand the roles of the cellular cytoskeleton and signal transduction pathways in the internalization of two E. tarda strains in EPC cells. The internalization of PPD130/91 and PPD125/87 was very sensitive to cytochalasin D, a specific blocker of actin polymerization. Inhibition of internalization by cytochalasin $\mathrm{D}$ was observed at concentrations as low as $0 \cdot 1 \mu \mathrm{g} \mathrm{ml}^{-1}$. Therefore, it is most likely that these two strains enter EPC cells by triggering rearrangements of the actin microfilament system. Genistein, a specific tyrosine kinase inhibitor, significantly inhibited internalization of the two E. tarda strains, suggesting that $E$. tarda internalization requires the involvement of protein tyrosine kinase. On the other 

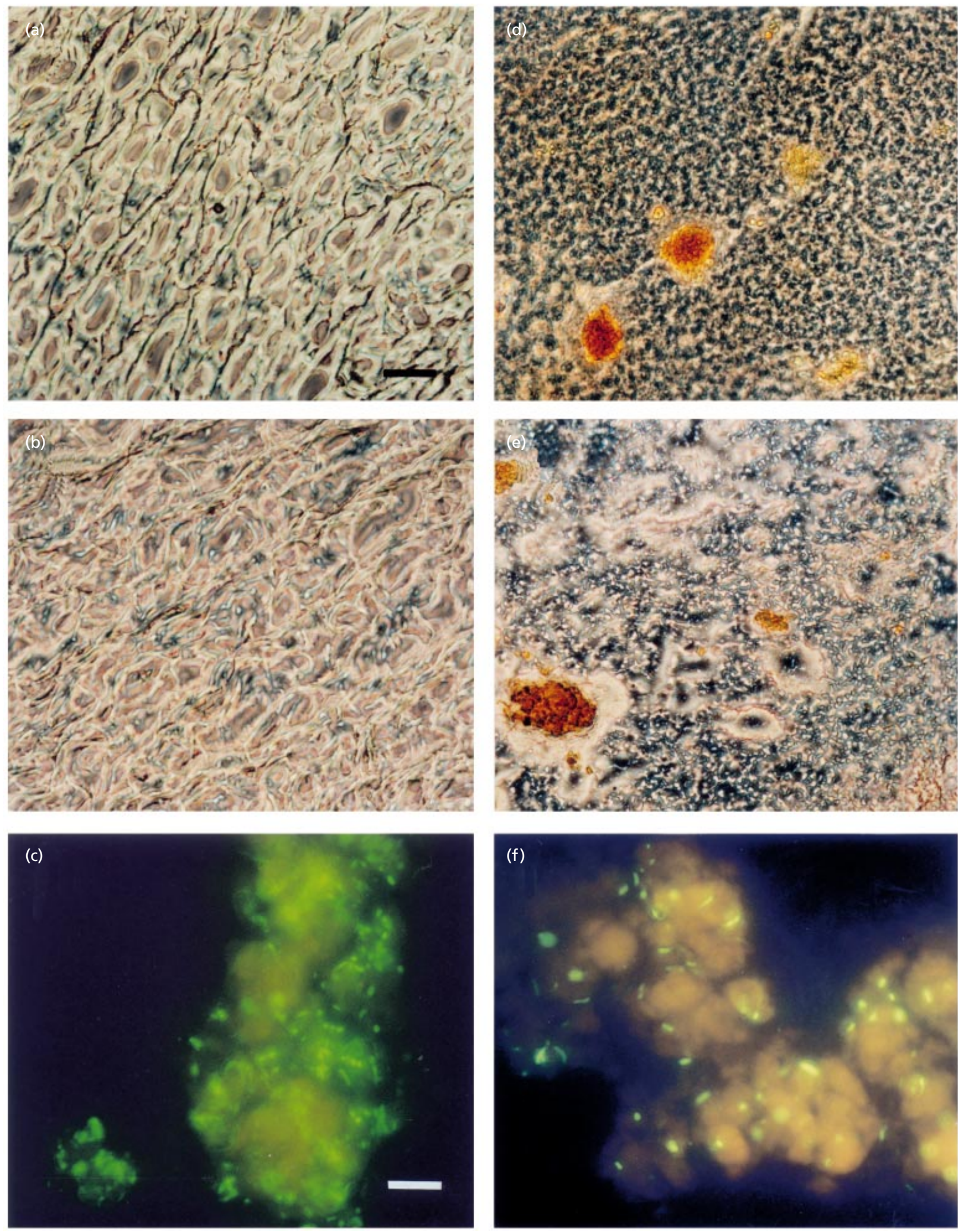

Fig. 3. Histological sections of the body muscle and liver of blue gourami. ( $a, b, d, e)$ Phase-contrast micrographs; (c, f) fluorescence micrographs. (a) Longitudinal section of body muscle from uninfected fish. (b) Longitudinal section of body muscle from PPD130/91(pGFPuv)-infected fish. (c) High magnification of muscle tissue shows numerous fluorescent bacteria. (d) Transverse section of liver from uninfected fish. (e) Transverse section of liver from PPD130/91(pGFPuv)infected fish. ( $f$ ) High magnification of liver section showing numerous fluorescent bacteria. Bars: (a) (also applies to b, $d$ and e) $50 \mu \mathrm{m}$; (c) (also applies to f) $10 \mu \mathrm{m}$. 
hand, staurosporine, a non-selective protein kinase $\mathrm{C}$ inhibitor, significantly accelerated internalization of PPD125/87. This chemical did not inhibit or accelerate the internalization of PPD130/91. PD098059, a mitogenactivated protein kinase (MAPK) kinase inhibitor, significantly inhibited the internalization of PPD130/91, but failed to have any effect on the internalization of PPD125/87 by EPC cells. None of the inhibitors interfered with bacterial viability or the viability of EPC cells (data not shown).

\section{Transformation of $E$. tarda with pGFPuv and pBFP2}

To study the invasion pathways of E. tarda inside EPC cells and in a fish host, pGFPuv and pBFP2 plasmids were transformed into these bacteria. These transformed strains fluoresced an intense green (pGFPuv) or blue (pBFP2) when illuminated with UV light. The stability of the two plasmids was tested in vitro, by subculturing in TSB daily for $7 \mathrm{~d}$, using E. tarda PPD130/91(pGFPuv) and PPD125/87(pBFP2), respectively, and was found to be maintained at $100 \%(n=3)$ in the strains. In our experiments done in vivo, bacteria that were recovered from various organs obtained from PPD125/87(pBFP2)infected fish still retained their fluorescence even on the fourteenth day after injection into the fish. These results suggest that fluorescent protein expression is very stable in the bacterial population. Transformed PPD125/87 and PPD130/91 had similar $\mathrm{LD}_{50}$ values, effects on EPC cell morphology, haemolysin production and serum survival ability as the untransformed strains (Table 1 ). Adherence rates of transformed PPD125/87 were lower but were still within the same range as other avirulent strains. Internalization rates of PPD125/87 after transformation remained the same. There was no change in the adherence and internalization rates of PPD130/91 after transformation with pGFPuv and $\mathrm{pBFP} 2$. Thus, the incorporation of pGFPuv and pBFP2 plasmids did not cause any significant changes in E. tarda virulence. We then chose PPD130/91(pGFPuv) and PPD125/ 87 (pBFP2) to study the bacterial-host interactions in vitro and in vivo.

\section{Evidence for $E$. tarda internalization}

Internalized E. tarda tagged with fluorescent protein could be visualized under the confocal microscope. Early in infection, the virulent strain, PPD130/91, multiplied inside EPC cells without any significant morphological change in the EPC cells (data not shown). Many tightly clustered E. tarda PPD130/91(pGFPuv) were seen inside the host cells 30 min post-inoculation. The monolayer and the cell nuclei appeared to be intact despite the presence of intracellular bacteria. At $8 \mathrm{~h}$ post-inoculation (Fig. 1a), the cell morphology had totally changed, cells becoming round, transparent and distorted. The nuclei of these infected cells had also disintegrated completely. Similarly, the avirulent strain PPD125/87 was found inside host cells after infection. However, in contrast to infection with PPD130/91, infected cells were already rounded and distorted, with most of the monolayer detached from the coverslip in the early stages of infection ( $3 \mathrm{~h}$ post-inoculation, data not shown). Fig. 1(a) is a high-power micrograph of an infected cell at its last stage ( $8 \mathrm{~h}$ post-inoculation) of infection with PPD130/91(pGFPuv). Bacteria were found inside the EPC cells by optical sectioning carried out serially at $2 \mu \mathrm{m}$ intervals along the $z$ axis. Many rodshaped E. tarda could be seen clearly in the mid-region (middle plane) of the infected cell, suggesting the cluster of bacteria was intracellular.

\section{Involvement of actin in $E$. tarda internalization}

Cytochalasin D significantly inhibited the internalization of PPD130/91 and PPD125/87 by EPC cells (Table 3). Confocal microscopy revealed patches of polymerized actin on the EPC cell surface which appeared to be co-localized with bacteria (Fig. 1b). Approximately $26 \%$ of early infected cells ( $30 \mathrm{~min}$ postinoculation) were observed to have co-localization of actin patches and bacteria. These results suggested that microfilaments were involved in bacterial internalization. A few actin patches (without colocalization with bacteria) were observed in the uninfected cells.

\section{Infection kinetics of $E$. tarda in fish}

Single infection kinetics of PPD130/91(pGFPuv) (Fig. 2a) and PPD125/87 (pBFP2) (Fig. 2b) and their untransformed counterparts (data not shown) were found to be similar. In single infections with E. tarda PPD130/ 91(pGFPuv), high bacterial numbers were detected in blue gourami (Fig. 2a). On day 1 of the experiment, they were highest in the body muscle - bacteria had multiplied 400 -fold $\left(4 \cdot 4 \times 10^{7}\right.$ c.f.u.). Bacteria were also detected in high numbers in the liver, followed by the kidney, blood, heart, spleen and gall bladder. By day 5, the bacterial population in the muscle had proliferated to $2 \cdot 1 \times 10^{9}$ c.f.u. In the fish organs, rapid bacterial growth was also observed - highest in liver, then in the kidney, spleen, heart, gall bladder, blood and intestine. Mortalities in the infected fish were observed from day 3 onwards and all were dead by day 5 of the experiment. On the other hand, in the single infections with PPD125/87(pBFP2) (Fig. 2b), there was a decline in the bacterial population over a period of $7 \mathrm{~d}$. Although bacteria were detected in all parts of the fish on day 1 , there was no significant growth. Body muscle only contained $3 \cdot 1 \times 10^{4}$ c.f.u. of PPD125/87(pBFP2). By day 7 of the experiment, there were insignificant numbers of bacteria in all organs except the spleen. No mortality was observed in these infected fish. In the mixed infections, both avirulent and virulent E. tarda were detected in blue gourami. On day 1, the PPD125/ 87 (pBFP2) population had multiplied 10 -fold in the body muscle and growth continued until day 3 (Fig. 2d), after which the population decreased. Numbers of PPD125/87(pBFP2) in the heart, kidney, spleen, liver and blood were higher than in the single infection. By day 5 , the number of PPD125/87(pBFP2) in the fish had fallen to low levels, but were slightly higher in the 
spleen. PPD130/91(pGFPuv) had multiplied 1000-fold in the body muscle by day 1 and growth persisted over the experimental period (Fig. 2c). However, the numbers of PPD130/91(pGFPuv) in the rest of the organs were lower than in the single infections and decreased by day 5. Despite the low numbers of both PPD130/91(pGFPuv) and PPD125/87(pBFP2) in the fish, mortalities were observed in the infected fish from day 3 onwards and the rest were dead by day 5 of the experiment.

\section{Histological examination of the body muscle and liver of blue gourami}

Fig. 3 shows micrographs of snap-frozen, unstained body muscle and liver sections from uninfected and infected blue gourami. In the uninfected fish, longitudinal skeletal muscle appeared as organized fibres (Fig. 3a). Sections of the body muscle from fish infected with the avirulent PPD125/87(pBFP2) were similar to those of the uninfected fish (data not shown). However, there was an evident pathological change in the body muscle sections from fish infected with the virulent PPD130/91(pGFPuv) strain (Fig. 3b). The muscle tissue appeared to be disorganized and irregularly shaped with numerous fluorescent PPD130/91(pGFPuv) observed in the muscle (Fig. 3c). The liver from uninfected fish showed organized hepatocytes (parenchymal cells) with melanomacrophage centres scattered throughout the parenchyma (Fig. 3d). The liver section from PPD125/ 87 (pBFP2)-infected fish was similar to that of the uninfected fish (data not shown). However, liver from PPD130/91(pGFPuv)-infected fish showed necrosis and had disorganized hepatocytes (Fig. 3e). Fluorescent PPD130/91(pGFPuv) were also observed in the infected liver (Fig. 3f).

\section{DISCUSSION}

In this study invasion pathways of E. tarda were studied in two host models, EPC cells and blue gourami, using fluorescent proteins. Bacteria with fluorescent proteins were visible inside infected hosts. E. tarda PPD130/91 and PPD125/87 were tagged with plasmids pGFPuv and pBFP2, respectively. Addition of fluorescent proteins was confirmed not to affect any E. tarda virulence characteristics such as capacity to induce morphological changes in EPC cells, serum survival rate, haemolysin production and $\mathrm{LD}_{50}$ values (Table 1 ). There was a slight change in adherence of PPD125/87(pBFP2) and PPD125/87(pGFPuv), but it was still within the range of other avirulent strains (Table 2). In other work done on Salmonella typhimurium, Yersinia pseudotuberculosis and Mycobacterium marium in vitro and in vivo, bacterial activity was also not compromised by GFP expression (Valdivia et al., 1996). In addition, in vitro and in vivo experiments showed that plasmid stability in the two E. tarda strains was $100 \%$, making this method a very stable and useful tool for future studies.

This is the first study on the interaction of E. tarda with fish epithelial cells in vitro. The epithelial cell line was used because it is likely to be the first cell type that a fish pathogen would encounter in vivo before establishing infection. Using our tissue culture model, E. tarda strains induced cytotoxic changes in EPC monolayers and two different types of pattern were observed. Rapidly cytotoxic (represented by PPD125/87) and slowly cytotoxic (represented by PPD130/91) strains have been identified among E. tarda (Table 1). In our study, rapid induction of cytotoxicity in EPC cells by E. tarda was not related to virulence in our fish model. Our results agreed with reports of other researchers. Janda et al. (1991a) suggested that haemolysins and other exoenzymes were responsible for the cytotoxic effect observed in HEp-2 cells. Later, they reported that haemolysins and other exoenzymes in E. tarda did not play a major role in bacterial virulence and subsequent establishment of disease in mice (Janda et al., 1991b). The slowly cytotoxic strains, such as PPD130/91 and AL9379, did not have drastic effects on host cell morphology for an extended period of time. The rapid continuous growth of E. tarda in MEM, after a long time, would eventually affect the integrity of the EPC monolayers. This failure to induce cytotoxic effects rapidly in vitro is also seen in human pathogens such as Shigella flexneri, Y. enterocolitica, and Salmonella species (Finlay \& Falkow, 1988, 1989).

Adherence to and invasion of host cells are often the initial steps of the pathway taken by many pathogenic bacteria (Finlay \& Cossart, 1997; Finlay \& Falkow, 1997). In our study, all the E. tarda strains adhered to and invaded EPC cells (Table 2). The adherence and internalization rates of E. tarda were much greater than those of other fish pathogens such as Vibrio species (Wang et al., 1998). The virulent strain, PPD130/91, entered fish cells efficiently, being found intracellularly at $30 \mathrm{~min}$ post-inoculation (data not shown).

Usually, antibody-labelled bacteria are visualized after fixing cells at different time points during infection, but this limits the tracing of the pathway taken by the live bacteria. Fluorescein dyes and commercial labels such as 'Live and Dead' (Molecular Probes) fade rapidly due to photobleaching and newly proliferated bacteria do not have sufficient stain to give a strong signal. Thus the true total bacterial population is underestimated. These conventional methods are also time-consuming and inconvenient. With GFP, E. tarda PPD130/91 was visualized easily under the confocal or epifluorescence microscope. These bacteria were able to survive and multiply over time while the EPC monolayer remained intact (data not shown). Our intracellular replication assays further supported the suggestion that PPD130/91 was able to multiply rapidly inside EPC cells. In later stages of infection, degeneration of cell nuclei and other cellular organelles could also be observed (Fig. 1a).

The mechanism employed by E. tarda to enter fish epithelial cells appears to be microfilament dependent (Fig. 1b). Cytochalasin D, a drug which inhibits actin filament polymerization, significantly inhibited the internalization of both PPD130/91 and PPD125/87 by EPC cells. Similar observations have also been reported by Janda et al. (1991a) on a human isolate of E. tarda 
where inhibitors of microfilaments (cytochalasins B and D) affected the invasive process. Polymerized actin filaments are part of the host cytoskeletal structure responsible for many active cell processes such as phagocytosis, cell movement and membrane ruffling. Actin polymerization has been associated with bacterial internalization by host cells in A. hydrophila (Tan et al., 1998), Shigella flexneri (Clerc \& Sansonetti, 1987) and Salmonella spp. (Finlay et al., 1991). GFP allowed us to visualize the association of E. tarda with actin polymerization.

In addition to recruitment of host cytoskeletal elements, there is increasing evidence for the induction of host cell signalling pathways by invasive bacteria. These bacteria are able to exploit the host cell's existing signalling pathways, including activation of protein tyrosine kinases and of phospholipase $\mathrm{C}$, leading to increased intracellular $\mathrm{Ca}^{2+}$ levels and protein kinase $\mathrm{C}$ activity, to stimulate their uptake. In the present study, genistein, a specific inhibitor of protein tyrosine kinase with negligible effect on the activity of other serine and threonine kinases (Akiyama et al., 1987), was found to inhibit the internalization of both PPD130/91 and PPD125/87. This finding suggests that E. tarda internalization involves protein tyrosine kinase activation. This seems to be a common mechanism among fish pathogens, including Vibrio spp. (Wang et al., 1998) and A. bydrophila (Tan et al., 1998), which also require the activation of protein tyrosine kinase for internalization. Staurosporine, a relatively non-specific protein kinase C inhibitor (Tamaoki et al., 1986), substantially accelerated the internalization of PPD125/87. This acceleration of invasion by staurosporine might be associated with some signalling pathways other than protein kinase C. It has been shown in rat PC12 cells that staurosporine enhanced tyrosine phosphorylation of certain proteins (Rasouly \& Lazarovici, 1994). If this is the case, then activation of tyrosine kinases may have enhanced the invasion of E. tarda and inhibition of tyrosine kinases with genistein blocked the internalization process. The internalization of E. tarda PPD130/91 by EPC cells probably involved MAPK kinase since PD098059, a MAPK kinase inhibitor, blocked internalization.

The pathogenesis of Edwardsiella infection is a complex interplay between the bacteria and different types of host cells. Although tissue culture models may be invaluable in gaining further understanding about the disease under study (Quinn et al., 1997), it is essential to examine the invasion pathway taken in a natural host to fully understand the pathogenesis of bacterial infections. Only a few studies have been done on infection kinetics of E. tarda in fish (Kusuda \& Ishihara, 1981; Rashid et al., 1997) and the pathogenesis of edwardsiellosis is not fully understood. In the previous studies, antibiotics were used as markers to tag E. tarda. This conventional method of bacterial detection is indirect and may overestimate the number of bacteria of interest. This point is important when bacterial sampling is done in the gastrointestinal tract of the experimental animal where a wide variety of bacteria is present. Identification of the bacteria introduced would be tedious and may not be $100 \%$ accurate. The use of fluorescent proteins is a direct and visual means of detection, effective in screening in the presence of other bacteria. In our study, the two chosen strains were characterized by various virulence factors and used as representatives of virulent and avirulent groups. An intramuscular infection model was used to simulate infection by physical injury under natural conditions. From our results, the ability of both virulent PPD130/91(pGFPuv) and avirulent PPD125/ 87(pBFP2) to spread to various organs within one day (Fig. 2a, b) indicated that they might be able to survive in the muscle and blood of blue gourami. Although both strains were serum-resistant (Table 1), they exhibited contrasting infection kinetics. PPD130/91(pGFPuv) proliferated very rapidly in all the fish organs (Fig. 2a), suggesting the presence of additional virulence factors that protected it against the host defence system. Bacterial numbers were highest in the body muscle, but there were substantial numbers in the other organs. In contrast, avirulent PPD125/87(pBFP2) was unable to grow inside the fish (Fig. 2b). Thus, virulence in E. tarda is multifactorial and is related to additional factors besides serum resistance, possibly including factors such as haemagglutination, production of haemolysins and siderophores, and ability to bind Congo red, as reported by Janda et al. (1991b).

In addition to examination of single infections, studies of mixed infections are also possible with two bacterial strains expressing different fluorescent proteins. Using fluorescent proteins, two bacterial populations can be differentiated confidently and easily. These infections yielded interesting information on the ability of two bacterial strains, each at doses below the $\mathrm{LD}_{50}$, to complement the pathogenicity of each other. In the presence of PPD130/91(pGFPuv), PPD125/87(pBFP2) was able to proliferate over the first day after infection, with bacterial numbers in the body muscle as high as $10^{7}$ cells $\mathrm{ml}^{-1}$ by day 3 (Fig. 2d). PPD125/87(pBFP2) may have gained some protection against the host defences from PPD130/91(pGFPuv). However, the benefits that PPD125/87(pBFP2) gained were short-lived, as seen by the subsequent decline in its population (Fig. $2 \mathrm{~d}$ ) and also in its inability to spread throughout the fish. Establishment of avirulent bacteria in the muscle early in infection may be possible because the body of a nonimmune host requires time to detect and elicit its defences against a new foreign agent (Iwama \& Nakanishi, 1996). This may explain why PPD125/ 87 (pBFP2) could proliferate in the muscle in the first $3 \mathrm{~d}$ after infection. After this time, the ensuing inflammation may elicit more effective defences. PPD125/87(pBFP2) may not be able to resist these host responses, unlike the virulent PPD130/91(pGFPuv) strain. Mortalities similar to those in single infections with PPD130/91(pGFPuv) were noted. High numbers of PPD130/91(pGFPuv) in the muscle and their presence in other organs of the fish may have contributed to the mortalities. Tissue culture studies indicated that both avirulent PPD125/87 and 
virulent PPD130/91 have the ability to adhere to and invade host cells, but avirulent E. tarda appears to lack the ability to spread in vivo (Evelyn, 1996).

Fluorescent proteins allow visualization of the association of bacteria with the host tissues in infection experiments. Histopathological studies confirmed the presence of PPD130/91(pGFPuv) in fish infected with this strain and the mixed inoculum (Fig. 3). Histological sections of fish that were infected with avirulent PPD125/87 (pBFP2) appeared to be similar to those from uninfected fish. Conventional histology using indirect antibody labelling requires longer processing times for bacterial detection, and is tedious and expensive. Using our methodology, bacteria in cryostat sections were directly visualized without any immunological treatment.

Our present study describes a novel method, using fluorescent proteins, to conveniently study PPD130/ 91(pGFPuv) and PPD125/87(pBFP2) in vitro and in vivo. We have found that avirulent and virulent E. tarda strains are mostly serum-resistant and are able to adhere to, enter and replicate in fish cells using internalization mechanisms involving host microfilaments and protein tyrosine kinase. Virulent PPD130/91(pGFPuv) has additional virulence factors that result in establishment of disease in fish. Fluorescent proteins have opened up the possibility of following infection by microscopy. Therefore, in future it will be possible to follow the bacterial infection at various time points, especially early in infection, using very low doses of E. tarda. Using this tool, bacterial-host interactions can be further investigated in pursuit of the identification of the virulence factors involved, thus contributing to our understanding of the pathogenesis of Edwardsiella infections.

\section{ACKNOWLEDGEMENTS}

The authors are grateful to the National University of Singapore for providing a research grant for this work. We would like to thank Dr P. Tang for helpful constructive criticism and Ms Y. P. Tan for her technical assistance. We also wish to thank Drs T. T. Ngiam and H. Loh at the Primary Production Department of Singapore and Dr John Grizzle at Auburn University, USA, for providing us with the E. tarda isolates. We are grateful to $\mathrm{Mr} \mathrm{H}$. K. Yip for taking the photographs.

\section{REFERENCES}

Ainsworth, A. J. \& Dexiang, C. (1990). Differences in the phagocytosis of four bacteria by channel catfish neutrophils. Dev Comp Immunol 14, 201-209.

Akiyama, T., Ishida, J., Nakagawa, S., Ogawara, H., Watanabe, S., Itoh, N., Shibuya, M. \& Fukami, Y. (1987). Genistein, a specific inhibitor of tyrosine-specific protein kinases. J Biol Chem 262, 5592-5595.

Amandi, A., Hiu, S. F., Rohovec, J. S. \& Fryer, J. L. (1982). Isolation and characterization of Edwardsiella tarda from fall chinook salmon (Oncorhynchus tshawytscha). Appl Environ Microbiol 43, 1380-1384.

Chalfie, M., Tu, Y., Euskirchen, G., Ward, W. W. \& Prasher, D. C.
(1994). Green fluorescent protein as a marker for gene expression. Science 263, 802-805.

Clerc, P. \& Sansonetti, P. J. (1987). Entry of Shigella flexneri into HeLa cells: evidence for directed phagocytosis involving actin polymerization and myosin accumulation. Infect Immun 55, 2681-2688.

Crameri, A., Whitehorn, E. A., Tate, E. \& Stemmer, W. P. C. (1995). Improved green fluorescence protein by molecular evolution using DNA shuffling. Nature Biotechnol 14, 315-319.

Elsinghorst, E. A. (1994). Measurement of invasion by gentamicin resistance. Methods Enzymol 236, 405-420.

Evelyn, T. P. T. (1996). Infection and disease. In The Fish Immune System-Organism, Pathogen, and Environment, pp. 339-359. Edited by G. Iwama \& T. Nakanishi. San Diego: Academic Press.

Farmer, J. J. \& McWhorter, A. C. (1984). Genus X. Edwardsiella. In Bergey's Manual of Systematic Bacteriology, 8th edn, vol. 1, pp. 486-491. Edited by J. G. Holt \& N. R. Krieg. Baltimore: Williams \& Wilkins.

Finlay, B. B. \& Cossart, P. (1997). Exploitation of mammalian host cell functions by bacterial pathogens. Science 276, 718-725.

Finlay, B. B. \& Falkow, S. (1988). Comparison of the invasion strategies used by Salmonella cholerae-suis, Shigella flexneri and Yersinia enterocolitica to enter cultured animal cells: endosome acidification is not required for bacterial invasion or intracellular replication. Biochimie 70, 1089-1099.

Finlay, B. B. \& Falkow, S. (1989). Salmonella as an intracellular parasite. Mol Microbiol 3, 1833-1841.

Finlay, B. B. \& Falkow, S. (1997). Common themes in microbial pathogenicity revisited. Microbiol Mol Biol Rev 61, 136-169.

Finlay, B. B., Ruschkowski, S. \& Dedhar, S. (1991). Cytoskeletal rearrangements accompanying Salmonella entry into epithelial cells. J Cell Sci 99, 283-296.

Hirono, I., Tange, N. \& Aoki, T. (1997). Iron-regulated haemolysin gene from Edwardsiella tarda. Mol Microbiol 24, 851-856.

Janda, J. M., Abbott, S. L. \& Oshiro, L. S. (1991a). Penetration and replication of Edwardsiella spp. in HEp-2 cells. Infect Immun 59, 154-161.

Janda, J. M., Abbott, S. L., Kroske-Bystrom, S., Cheung, W. K. W., Powers, C., Kokka, R.P. \& Tamura, K. (1991b). Pathogenic properties of Edwardsiella species. J Clin Microbiol 29, 1997-2001.

Kubota, S. S., Kaige, N., Miyazaki, T. \& Miyashita, T. (1981). Histopathological studies on edwardsiellosis of tilapia. I. Natural infection. Bull Fac Fish Mie Univ 9, 155-165.

Kusuda, R. \& Ishihara, S. (1981). The fate of Edwardsiella tarda bacteria after intramuscular injection of eels, Anguilla japonica. Bull Jpn Soc Sci Fish 47, 475-479.

Leung, K. Y. \& Finlay, B. B. (1991). Intracellular replication is essential for the virulence of Salmonella typhimurium. Proc Natl Acad Sci USA 88, 11470-11474.

Leung, K. Y., Yeap, I. V., Lam, T. J. \& Sin, Y. M. (1995). Serum resistance as a good indicator for virulence in Aeromonas bydrophila strains isolated from diseased fish in South-East Asia. J Fish Dis 18, 511-518.

Meyer, F. P. \& Bullock, G. L. (1973). Edwardsiella tarda, a new pathogen of channel catfish (Ictalurus punctatus). Appl Microbiol 25, 155-156.

Nakatsugawa, T. (1983). Edwardsiella tarda isolated from cultured young flounder. Fish Pathol 18, 99-101.

Plumb, J. A. (1993). Bacterial Diseases of Fish. Edited by N. R. 
Bromage, V. Inglis, \& R. J. Roberts. Oxford: Blackwell Scientific Publications.

Prasher, D. C., Eckenrode, V. K., Ward, W. W., Prendgast, F. G. \& Cormier, M. J. (1992). Primary structure of the Aequorea victoria green-fluorescent protein. Gene 111, 229-233.

Quinn, F. D., Newman, G. W. \& King, C. H. (1997). In search of virulence factors of human bacterial disease. Trends Microbiol $\mathbf{5}$, 20-26.

Rashid, M. M., Nakai, T., Muroga, K. \& Miyazaki, T. (1997). Pathogenesis of experimental edwardsiellosis in Japanese flounder Paralichthys olivaceus. Fish Sci 63, 384-387.

Rasouly, D. \& Lazarovici, P. (1994). Staurosporine induces tyrosine phosphorylation of a $145 \mathrm{kDa}$ protein but does not activate gp140trk in PC12 cells. Eur J Pharmacol 269, 255-264.

Reed, L. J. \& Muench, H. (1938). A simple method of estimating fifty per cent end points. Am J Hyg 27, 493-497.

Rosenshine, I., Donnenberg, M. S., Kaper, J. B. \& Finlay, B. B. (1992). Signal transduction between enteropathogenic Escherichia coli (EPEC) and epithelial cells: EPEC induces tyrosine phosphorylation of host cell proteins to initiate cytoskeletal rearrangement and bacterial uptake. EMBO J 11, 3551-3560.

Sae-Oui, D., Muroga, K. \& Nakai, T. (1984). A case of Edwardsiella tarda in cultured colored carp, Cyprinus carpio. Fish Pathol 19, 197-199.

Sambrook J., Fritsch, E. F. \& Maniatis, T. (1989). Molecular Cloning: a Laboratory Manual, 2nd edn. Cold Spring Harbor, NY: Cold Spring Harbor Laboratory.

Strauss, E. J., Ghori, N. \& Falkow, S. (1997). An Edwardsiella tarda strain containing a mutation in a gene with homology to $s h l \mathrm{~B}$ and $h p m \mathrm{~B}$ is defective for entry into epithelial cells in culture. Infect Immun 65, 3924-3932.

Suprapto, H., Hara, T., Nakai, T. \& Muroga, K. (1996). Purification of a lethal toxin of Edwardsiella tarda. Fish Pathol 31, 203-207.

Tamaoki, T., Nomoto, H., Takahashi, I., Kato, Y., Morimoto, M.
\& Tomita, F. (1986). Staurosporine, a potent inhibitor of phospholipid $/ \mathrm{Ca}^{2+}$ dependent protein kinase. Biochem Biophys Res Commun 135, 397-402.

Tan, E., Low, K. W., Wong, W. S. F. \& Leung, K. Y. (1998). Internalization of Aeromonas hydrophila by fish cells can be inhibited with a tyrosine kinase inhibitor. Microbiology 144, 299-307.

Ullah, M. A. \& Arai, T. (1983). Pathological activities of the naturally occurring strains of Edwardsiella tarda. Fish Pathol 18, $65-70$.

Valdivia, R. H., Hromockyj, A. E., Monack, D., Ramakrishnan, L. \& Falkow, S. (1996). Applications for green fluorescent protein (GFP) in the study of host-pathogen interactions. Gene 173, 47-52.

Van Damme, L. R. \& Vandepitte, J. (1984). Isolation of Edwardsiella tarda and Plesiomonas shigelloides from mammals and birds in Zaire. Rev Elev Med Vet Pays Trop 37, 145-151.

Wakabayashi, H. \& Egusa, S. (1973). Edwardsiella tarda (Paracolobactrum anguillmortiferum) associated with pond-cultured eel disease. Bull Jpn Soc Sci Fish 39, 931-936.

Wang, X. H., Oon, H. L., Ho, G. W. P., Wong, W. S. F., Lim, T. M. \& Leung, K. Y. (1998). Internalization and cytotoxicity are important virulence mechanisms in vibrio-fish epithelial cell interactions. Microbiology 144, 2987-3002.

White, F. H., Simpson, C. F. \& Williams, L. E. (1973). Isolation of Edwardsiella tarda from aquatic animal species and surface waters in Florida. J Wildl Dis 9, 204-207.

Wolf, K. \& Mann, J. A. (1980). Poikilotherm vertebrate cell lines and viruses, a current listing for fishes. In Vitro 16, 168-179.

Received 21 June 1999; revised 20 September 1999; accepted 4 October 1999. 